\title{
La belleza actualista de la ciudad: tensiones de lo moderno en El pentagrama eléctrico de Salvador Gallardo
}

The city's current beauty: modern tensions in El pentagrama eléctrico by Salvador Gallardo

\author{
ANUAR JALIFE JACOBO \\ ORCID: 0000-0003-2555-6753 \\ Universidad de Guanajuato, México \\ anuarjalife@ugto.mx
}

Resumen:

Los estridentistas concibieron a la ciudad moderna como un espacio que brindaba las imágenes de lo actual y daba forma a una nueva sensibilidad. El presente artículo analiza los poemas de El pentagrama eléctrico (1925) de Salvador Gallardo, con la finalidad de mostrar las tensiones que se dan en el seno de la ciudad moderna, entre lo maquinal y lo afectivo, entre lo cambiante y lo permanente, entre el mundo exterior y el interior. Esto como una manera de revalorar la poesía estridentista a 100 años de la aparición del movimiento.

Palabras clave:

Salvador Gallardo, El pentagrama eléctrico, ciudad, modernidad, estridentismo.

Abstract:

The Estridentistas conceived the modern city as a space that provided the images of the present and shaped a new sensibility. This article analyzes the poems of El pentagrama eléctrico 
(1925) by Salvador Gallardo in order to show the tensions that exist within the modern city, between the mechanical and the affective, between the changing and the permanent, between the outer and inner world. This as a way to revalue the Estridentista poetry 100 years after the appearance of the movement.

Keywords:

Salvador Gallardo, El pentagrama eléctrico, City, Modernity, Estridentism.

DOI: https://doi.org/10.36798/critlit.v0i23.381

Recibido: 25 de febrero de 2021

Aceptado: 04 de mayo de 2021

A Salvador Gallardo Cabrera

\section{Introducción}

En su famoso libro dedicado a Constantine Guy, pintor que capturó la vida cotidiana de la renovada París del Segundo Imperio, Baudelaire definía la modernidad como "lo transitorio, lo fugitivo, lo contingente" (91), y consagraba al artista la tarea de extraer lo que esta pudiera poseer de poético, eterno e inmutable. Desde entonces, la ciudad se ha presentado como el horizonte de lo actual, como el espacio de las multitudes y las modas, de las novedades tecnológicas y los cambios de costumbres, de la velocidad y la transformación. En México, la ciudad moderna fue adquiriendo carta de naturaleza literaria, como escenario primero y como protagonista después, principalmente en las obras de los novelistas y cronistas decimonónicos, de José Joaquín Fernández de Lizardi a Manuel Gutiérrez Nájera, de Guillermo Prieto a Ángel de Campo, de Francisco Zarco a Tomás de Cuéllar, quienes delinearon su cambiante fisonomía, otorgaron rostro a sus nuevos personajes y dieron cuenta de la vida 
que se desarrollaba en sus calles. Sin embargo, aun con el antecedente marcado por poetas como Ramón López Velarde, es hasta el surgimiento del estridentismo, a comienzos de la década de 1920, que la ciudad moderna apareció en la poesía mexicana con todo su fulgor y estrépito.

Para Vicente Quirarte, los estridentistas "hicieron de la ciudad el escenario fundamental de sus acciones y ... quisieron hacer de ella la prueba más elocuente de su actualidad: los poetas anteriores a ellos — esos que Maples Arce se sintió en la necesidad moral e intelectual de cuestionar o rechazar - habían hablado de la ciudad con un sentido de permanencia, no como un organismo vivo, en mutación constante" (477). Desde su gesto fundacional, el estridentismo incorporó a la ciudad no solo como paisaje, motivo o personaje, sino como un territorio poético y vital que procuraba una nueva sensibilidad y una nueva forma de existencia. Se trataba de una ciudad al mismo tiempo referencial e imaginaria; una ciudad que más que descrita aparecía invocada como encarnación del presente y germen del futuro; una ciudad activa que se transformaba a sí misma y a sus habitantes. La ciudad fue concebida por los vanguardistas mexicanos como la síntesis de un espacio y un tiempo nuevos; concepción que entrañaba un profundo rechazo al pasado, pero también una crítica al presente y que, en consecuencia, demandaba a los artistas la creación de formas de expresión poéticas y actitudes culturales que fueran no solo distintas a las consagradas por la tradición sino cuestionadoras de su propio tiempo. ${ }^{1}$

De esta manera, alejado de las viejas prácticas literarias, renuente a los salones, los estudios o las bibliotecas, asociados a los ateneos y liceos del XIX, el estridentismo eligió elocuentemente la calle como espacio para su irrupción inaugural, ${ }^{2}$ cuando a fines de diciembre

${ }^{1}$ De acuerdo con Peter Bürger, en su crítica a la modernidad "la gran ciudad proporciona el ámbito idóneo para la práctica vanguardista por cuanto acentúa la condición de extrañamiento, tanto del artista como de su práctica, respecto a los valores que controlan la convivencia" (11).

2 Para Renato Poggioli: "Si la vanguardia tiene un código de conducta, 
de 1921, un entonces solitario Manuel Maples Arce tapizó los principales cuadros de la Ciudad de México y su barrio universitario con la hoja volante Actual $N^{0} 1$. Hoja de vanguardia. Comprimido estridentista ${ }^{3}$ primer manifiesto del movimiento que hacía un llamado a la juventud mexicana a la renovación literaria en un contexto de profundos cambios sociales. Para Yanna Hadatty Mora, en el manifiesto se advierte la mirada ambivalente que Maples Arce dirige a la ciudad: "el devaneo entre el reconocimiento de la vieja Ciudad de México, inamovible y real, y el deseo de modernidad que traza sobre sus calles y muros la posibilidad . . de desdibujarla" (29). A partir de ese momento, la ciudad con sus nuevos objetos y espacios, imaginarios y referenciales —aviones, tranvías y automóviles, rascacielos, cines y cabarets - se convirtió en la protagonista indiscu-

éste consiste en una perversión subversión integral del código de conducta convencional, de las reglas de urbanidad y de las buenas maneras. De aquí las normas de conducta invertidas que se pueden definir con los vocablos excentricidad y exhibicionismo" (49). En México, un antecedente de estos modos de acción literaria ubicados en la calle como espacio público se encontraría en la "Protesta literaria" y en la posterior manifestación que los jóvenes ateneístas emprendieron contra la publicación de una segunda etapa de la Revista Azul por parte de Manuel Caballero, quien a consideración de la juventud literaria de México traicionaba el legado del modernismo, y de Manuel Gutiérrez Nájera. La "Protesta", publicada el 7 de abril de 1907, funcionó como un manifiesto grupal y se vio acompañada por una manifestación pública de jóvenes estudiantes que tomaron las calles del centro de la Ciudad de México. Para una revisión de este episodio puede consultarse la tesis doctoral de Ernesto Sánchez Pineda, "Prolegómenos al Ateneo de la Juventud y la figura del intelectual moderno (1900-1909)" (2008).

${ }^{3}$ Maples Arce recuerda en el segundo tomo de sus memorias: "Me puse a escribir un manifiesto. Apenas redactado éste, me fui a la imprenta de la Escuela de Huérfanos. La hoja impresa en papel Velia de colores se titulaba Actual. Destacaban en ella los títulos: 'Muera el cura Hidalgo', 'Abajo San Rafael-San Lázaro', 'Chopin a la silla eléctrica', y otros lemas en que había concentrado mi furor. // El manifiesto fue fijado una noche, junto a los carteles de toros y teatros, en los primeros cuadros de la ciudad y, principalmente, por el barrio de las facultades. Se distribuyó a los periódicos y se mandó por correo a diversas personas de México y el extranjero" (Soberana 84). 
tible de las obras poéticas, narrativas y plásticas del movimiento de vanguardia mexicano.

\section{El pentagrama eléctrico de Salvador Gallardo}

Médico militar y revolucionario, Salvador Gallardo Dávalos fue uno de los jóvenes escritores que respondieron a la convocatoria de Maples Arce. ${ }^{4}$ A comienzos de 1920, en la ciudad de Puebla, trabó amistad con Germán List Arzubide y Miguel Aguillón Guzmán. Junto con ellos editó la revista Ser, en 1922, y a fines de ese año se sumó al estridentismo, figurando entre los firmantes del segundo Manifiesto Estridentista, publicado el $1^{\circ}$ de enero de 1923. A partir de ese momento, se convirtió en colaborador de las empresas más significativas del movimiento.

En su alucinante crónica sobre la historia del grupo, El movimiento estridentista, List Arzubide recrea así el encuentro entre Gallardo y el autor de Andamios interiores:

Maples Arce recibió un día la carta sin rumbo fijo enviada por list arzubide [sic], presentándole a un compañero; las señas coincidían: un rostro alejado de abandono, donde los espejuelos se empañaban de citas de mujeres. Entregó sus credenciales: dos poemas estridentistas abarrotados de asombros viajeros, y regresó a los abrazos de paga; era el Dr. Salvador Gallardo.

${ }^{4}$ Salvador Gallardo nació en Río Verde, San Luis Potosí en 1893. En 1910 se trasladó a la capital del estado para ingresar al Instituto Científico Literario y posteriormente comenzar sus estudios de medicina, los cuales concluiría en 1918 en la Escuela Médico Militar de la Ciudad de México. En 1913, después de que Madero fuera asesinado, decidió unirse a la Revolución, siguiendo los pasos del coronel potosino Rafael Nieto, y durante toda la década participó en distintos frentes a lo largo del país. En 1920, encontrándose en la ciudad de Puebla con un contingente revolucionario, conoció a Germán List Arzubide y Miguel Aguillón Guzmán, con quienes se sumaría al movimiento estridentista (López 16-27). 
Maples Arce le pagó la visita yendo a buscarlo a su consultorio, donde el Dr. Gallardo curaba con promesas a una clientela sin oficios. Durante la hora que Maples Arce estuvo allí, llegaron muchos hombres a curarse de males que no están en los catálogos; felizmente para Gallardo los hombres tenían un troquel infranqueable y fueron reconocidos como el único. Maples Arce advirtió por este planteamiento y superación de gentes, que Salvador Gallardo era un gran poeta (El movimiento 35-6)

En julio de 1925, Gallardo dio a conocer el tercer Manifiesto Estridentista en la ciudad de Zacatecas, y en diciembre de ese mismo año sacó a la luz El pentagrama eléctrico, publicado por la Casa Editora de Germán List Arzubide. El poemario apareció con una presentación de List, titulada "Peldaño", en la que se celebraba la incorporación del libro "rotundo y trepador" del potosino a la biblioteca estridentista en un momento destacado de la producción literaria del grupo: “el minuto lombriciento de la 'Urbe' que existe por el poema súper-bolchevique. Cuando la Señorita Etcétera, de Arqueles, vela aun como amada de todos los concursos y Germán List Arzubide, dice en la 'Esquina' el mensaje de los últimos crucificados de la civilización: los gendarmes del tráfico" (List, "Peldaño" 10).

La ilustración de los forros corrió a cargo de Ramón Alva de la Canal, quien también incluyó un retrato caricaturesco del autor, cuya efigie recuerda a la que el propio pintor plasmó en su famoso cuadro El café de nadie. La imagen de la portada (Fig. 1), donde se manifiesta una tensión cromática entre el rojo y el negro, ${ }^{5}$ es una combinación de figuras geométricas y orgánicas. El título del poemario y el nombre del autor, compuestos con una gruesa y desarre-

${ }^{5} \mathrm{Al}$ respecto, Marina Garone Gravier afirma que los manifiestos vanguardistas - a los que podríamos sumar otros objetos editoriales como libros y revistasescapan de los convencionalismos de la organización gráfica y textual mediante diversas "operaciones de intervención gráfica", entre la cuales se encuentra "la tensión cromática entre colores opuestos o complementarios (rojo sobre negro u otro tipo de combinaciones binarias y usualmente opuestas)" (112-3). 
glada caligrafía, ocupan las partes superior e inferior de la portada, respectivamente. Se ubica en la base, en un primer plano, una sólida plasta negra con bordes dentados. Sobre ella, en un segundo plano, donde predomina el color rojo, descansa una pirámide de la cual emanan una serie de líneas de fuga que se abren angularmente hacia la parte superior izquierda y que podrían representar —en alusión al título del libro - una telaraña de cables eléctricos o una irradiación o explosión acompañada de líneas curvas que parecen nubes. Entre las líneas de fuga se entrecruzan otras pirámides más pequeñas. Finalmente, cargada hacia la esquina superior derecha, surge una figura negra circular, también dentada, que podría representar una suerte de sol negro. El conjunto parece componer un paisaje abstracto y caótico. Sin embargo, desde otra perspectiva, también podemos apreciar la figuración de un rostro cadavérico pero afable, ligeramente reclinado hacia la izquierda. Una plasta negra y curveada, colocada hacia el margen interior, podría representar su cabello e insinuar el contorno de la cara. La boca podría ser una cruz o una $\mathrm{X}$, mientras que las concavidades de los ojos y la nariz estarían formadas por figuras triangulares. Sobre una de ellas aparecen una serie de líneas gruesas, cortas y ligeramente curveadas que podrían representar una ceja. Más allá de lo que podamos imaginar, la ambigüedad y la simultaneidad de los sentidos que posee la imagen, así como la invitación al espectador para asumir una perspectiva y participar activamente en la construcción del cuadro, se encuentran en profunda relación con la estética estridentista y establecen un diálogo complementario con El pentagrama eléctrico, pues, como afirma Elissa J. Rashkin a propósito de los objetos de vanguardia, " desde una perspectiva histórica, los textos son más que poemas; también se componen ... de la totalidad de la página impresa o del volumen, incluidas la tipografía y las ilustraciones” (34-5). 


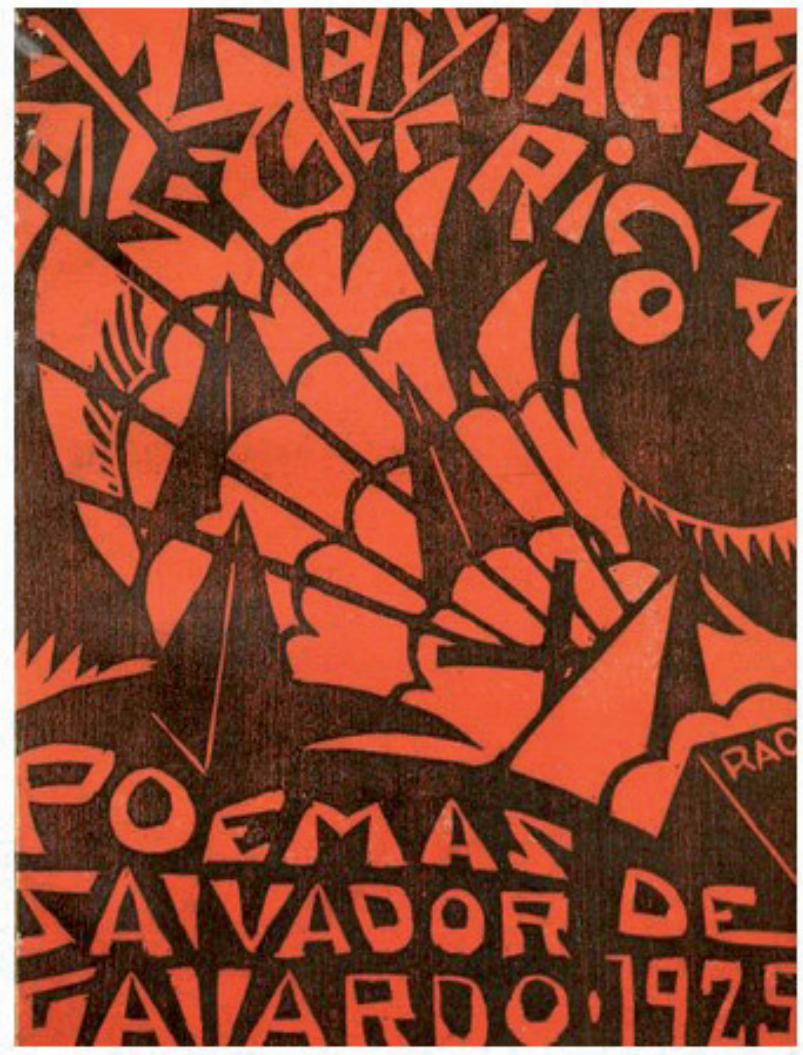

Figura 1. Portada de El pentagrama eléctrico. Poemas, de Salvador Gallardo, diseño y composición de Ramón Alva de la Canal, Casa Editora de Germán List Arzubide, 1925. Créditos de la imagen: Museo Nacional de Arte, INBA, donación de Blanca Vermeersch Vda. de Maples Arce, 1992.

El título del poemario se debe a unos versos de "En la dolencia estática", poema de Andamios interiores, de Maples Arce, que funcionan como epígrafe del libro:
Y el pentagrama eléctrico
de todos los tejados
Se muere en el alero del último almanaque 
El pentagrama eléctrico está integrado por 11 poemas breves: "Pentagrama", "Jardín", "Cámara obscura", "Carrousel”, "Cabaret", "Naufragio", "Alarma!!”, "Escalamiento", "Film”, "Corto-circuito" y "Puerto", en los cuales Gallardo echa mano de los recursos retóricos predilectos del grupo: el uso de la metáfora - principalmente prosopopeyas y sinestesias-, la fragmentación de la sintaxis, la variación de la métrica tradicional, el empleo de mayúsculas y signos de admiración, y el desacomodo tipográfico. ${ }^{7}$ Los ambientes y objetos, primordialmente urbanos, hacen eco de los que aparecen en otros libros estridentistas como Andamios interiores y Urbe de Maples Arce o Esquina de List Arzubide, donde, como pedía el veracruzano desde el primer manifiesto, se exaltaba la nueva belleza del siglo, la belleza actualista de las máquinas. ${ }^{8}$

${ }^{6}$ Una versión previa de este poema aparece en el primer número de Irradiador (1923).

En palabras de Luis Mario Schneider, "el vocabulario se reduce, principalmente, a fijar elementos de significaciones con la vida moderna y el ritmo de la ciudad: semáforos, trenes, automóviles, telégrafos, jazz, rascacielos, asfalto, etc., como todo libro estridentista" (146). Elissa J. Rashkin, por su parte, comenta que los poemas "están cargados con elementos característicos de la vanguardia: metáforas compuestas, frases resaltadas con mayúsculas y signos de exclamación, referencias a la gasolina, el jazz, las máquinas, los autos, el cine, las huelgas, la electricidad, el ruido y la disonancia" (251).

${ }^{8}$ En el punto IV de Actual No. 1, Maples Arce escribe: "Es necesario exaltar en todos los tonos estridentes de nuestro diapasón propagandista, la belleza actualista de las máquinas, de los puentes gímnicos reciamente extendidos sobre las vertientes por músculos de acero, el humo de las fábricas, las emociones cubistas de los grandes trasatlánticos con humeantes chimeneas de rojo y negro anclados horoscópicamente .. . junto a los muelles efervescentes y congestionados, el régimen industrialista de las grandes ciudades palpitantes, las bluzas [sic] azules de los obreros explosivos en esta hora emocionante y conmovida; toda esta belleza del siglo, tan fuertemente intuida por Emilio Verhaeren, tan sinceramente amada por Nicolás Beaudin, y tan ampliamente dignificada y comprendida por todos los artistas de vanguardia” (269). 


\section{Imágenes actuales, imágenes de lo actual}

Una de las cuestiones más llamativas de El pentagrama eléctrico son sus imágenes. A decir de Clemencia Corte Velasco, "el Estridentismo centró sus esfuerzos en la semántica poética” (92), particularmente en la creación de lo que llamaron equivalencias, fundamento poético de las audaces metáforas que caracterizan su poesía. En $A c$ tual No. 1, donde se perfila la poética estridentista, aparecen algunas ideas que arrojan luz sobre la noción de equivalencia y su importancia para la poesía del grupo. El autor de Urbe cree que al artista moderno le corresponde expresar su propio tiempo — “vanguardia actualista de México" llamó a su movimiento en la introducción del manifiesto-, y considera que cuando los medios expresivos existentes son incapaces de cumplir con esta misión, es necesario emprender una renovación radical:

Toda técnica de arte, está destinada a llenar una función espiritual en un momento determinado. Cuando los medios expresionistas son inhábiles o insuficientes para traducir nuestras emociones personales —única y elemental finalidad estética-, es necesario . . cortar la corriente y desnucar los 'swichs'. (Actual 268)

Para los estridentistas, el signo de los tiempos, lo actual, se manifiesta en lo urbano. La ciudad es a la vez un punto de encuentro e irradiación del presente. Los nuevos escenarios, los nuevos objetos, las nuevas relaciones sociales y el impacto que estos tienen en la subjetividad representan lo distintivo del siglo que despunta. Sin embargo, para Maples Arce la verdad posee un carácter subjetivo, "las cosas no tienen un valor intrínseco posible" y, por lo tanto, no basta con incorporar en el arte las novedades del siglo XX de forma realista o mimética. En lugar de esto, el poeta moderno debe encontrar la "equivalencia poética" de las cosas por medio de un acto creativo y no imitativo, debe descubrir y recrear las "relaciones y coordinaciones" que el mundo exterior establece emotiva e intelectualmente con el interior (Actual 268): "Yo había pensado reiteradamente en el problema de la renovación literaria de manera 
inmediata, en ahondar las posibilidades de la imagen, prescindiendo de los elementos lógicos que mantenían su sentido explicativo", escribe Maples Arce en sus memorias (Soberana 122). Se trata de la búsqueda de una "poesía pura", un concepto caro a diversas tendencias poéticas de los años veinte, que adquiere distintos sentidos dependiendo de cada corriente. ${ }^{9}$ En este caso, se trata de una poesía realizada con "elementos propios y congénitos fecundados en su propio ambiente", y en la que se elimine "todo elemento extraño y desnaturalizado (descripción, anécdota, perspectiva)" (Actual 272). Para ello, el estridentismo se postula como una "síntesis quinta-esencial y depuradora" de otros movimientos vanguardistas (creacionismo, dadaísmo, paroxismo, expresionismo, etc.), no con un afán meramente conciliador sino con la intención de dar forma a una nueva técnica que permita "totalizar las emociones interiores y sugestiones sensoriales en forma multánime y poliédrica"; es decir, una técnica que en su trabajo de expresión de la dialéctica de lo exterior y lo interior, pueda recrear con toda su complejidad y amplitud, la "arbitrariedad y desorden específico" de las emociones y la simultaneidad e intermitencia de los pensamientos (Actual271).

En esta exploración técnica, como se decía líneas arriba, ocupa un lugar fundamental el concepto de equivalencia o imagen equivalente, esto es, una metáfora que conjuga de forma simultánea una visión subjetiva con una objetiva, una imagen con la cual, dice List Arzubide, "la visión material de la frase, baraja simultáneamente la abstracción emotiva tendiendo a afirmar la realidad misteriosa y logrando que tal realidad haga asequible el sentimiento de lo subjetivo, alcanzando con esto, transformar todo en emoción" (Elmovimiento 116). El propio Salvador Gallardo, en un discurso de presentación de El pentagrama eléctrico, ${ }^{10}$ en el que enmarca al estridentismo en el hori-

${ }^{9}$ De acuerdo con Anthony Stanton, a lo largo de los años 20 conviven cinco nociones de poesía pura: la del abate Henri Bremond, la de Paul Valéry, la "poesía desnuda" de Juan Ramón Jiménez, la de los poetas vanguardistas y la de José Ortega y Gasset (28-31).

${ }^{10} \mathrm{El}$ discurso de presentación se encuentra recopilado en el libro Un suspiro 
zonte histórico de los movimientos de vanguardia, hace referencia a esta poética de la equivalencia como un rasgo distintivo de la poesía de su grupo. El poeta reconoce en el expresionismo una crítica social contra las dictaduras; en el cubismo, una expresión de la esencia de la realidad, una ruptura con el pasado y una lógica distinta a la racionalista; en el futurismo, una ruptura con la tradición "con pretensiones de una filosofía socialista y de una nueva religión, la de la velocidad; adoración de la máquina y proyección del futuro" (cit. en López 51). Hay algo de todo eso en el estridentismo, afirma, pero también hay algo distinto. En lo que corresponde al movimiento mexicano, Gallardo pone el acento en la búsqueda de una imagen y una sintaxis nuevas:

También suprimimos la descripción lineal y lógica, porque la emoción necesita de otro lenguaje. Así hicimos uso de imágenes no gráficas y naturales, sino reconstruyéndolas y recreándolas al juntar su esencia con otras equivalentes y semejantes.

Más que de la lógica formal hicimos uso de la dialéctica con la destrucción de la imagen por una imagen contraria para obtener así una imagen nueva, obligando también al lector a descifrarla y entender para que sea también su creador. (cit. en López 51-2)

Las palabras del potosino conectan con lo que Poggioli reconoce como uno de los fundamentos de la poética vanguardista: la "metafísica de la metáfora”, es decir, "una concepción metafórica del lenguaje, considerado no como figuración, sino transfiguración de lo real" (205). Asimismo, muestran la consciencia de otra de las búsquedas primordiales de las poéticas vanguardistas, que es el res-

fugaz de gasolina de Leticia López. Desafortunadamente, la autora no consigna la fecha en que se pronunció este discurso, aunque está claro que no se trató de la presentación de la primera edición, pues en él hace referencia al nazismo. Quizás se trate de una presentación a alguna de las dos ediciones de Laberinto de quimeras $(1955,1966)$ donde, según Luis Mario Schneider, El pentagrama eléctrico fue incluido. 
quebrajamiento de la inminencia del poema, al demandar la participación del lector en la recreación de la imagen poética. Para los estridentistas, la equivalencia poética significó un camino para ser escritores de un tiempo nuevo; fue un recurso que les permitió poner en relación su propia interioridad con el desbordado orbe de lo moderno, encarnado en lo urbano, lo maquinal, lo tecnológico.

\section{El poeta y la belleza actualista de las máquinas}

"Pentagrama", el poema con que abre el libro, nos introduce, mediante una serie de imágenes equivalentes, en el ambiente citadino y en ese movimiento de ida y vuelta de lo exterior a lo interior que marca el ritmo conceptual de todo el poemario. En este caso, se trata de la esquina de una calle moderna, espacio frecuentado por la gráfica y la poesía estridentista como imagen de la ciudad moderna, pero también como representación, de inspiración cubista, de planos espacio-temporales simultáneos y superpuestos. ${ }^{11} \mathrm{El}$ poema de Gallardo dialoga con "Esquina" del libro homónimo de List Arzubide, en el cual vemos el vértigo del tránsito citadino:

Un discurso de Wagner

es bajo la batuta del

ALTO-Y-ADELANTE

La calle se ha venido toda tras de nosotros

y la sonrisa aquella se voló de mis manos

$\mathrm{El}$ sol te ha desnudado.

..

Lazaró-Lazaró

el viaje a Marte al fin se hará en camión. (Esquina 405)

${ }^{11}$ La imagen de la esquina aparece en el estridentismo desde Actual No. 1, como parte de las consignas iniciales del manifiesto y reaparece numerosas veces en poemas de Maples Arce como "Todo en un plano oblicuo" y "Como una gotera"; "Esquina", "Silabario" y "La novia extra” de List Arzubide; "Las 13" de Miguel Aguillón Guzmán y "Pellizco” y "Bohemia” de Luis Quintanilla. 
En "Pentagrama" se presenta el instante de una calle capturado casi fotográficamente en el breve lapso que dura el cambio de luces de un semáforo:

Pentagrama

El álbum de las calles

se enrolla en los motores

Con fugas de los postes

que escriben sinfonías

$\mathrm{Y}$ un azoro embobado

se pega en las vitrinas

Los autos pederastas

desfloran el crepúsculo

Y las marcas comerciales

prenden sus constelaciones.

Sobre la acera encerada

las lunas juegan boliche.

¡ALTO! EVITE-PELIGRO

$\mathrm{Y}$ ante el mandato verde de tus ojos

Toda mi alma se ha desparramado. $(440)^{12}$

Cables, vitrinas, automóviles, aceras, semáforos, integran un paisaje prosopopéyico en el que se presenta a una ciudad viviente, pintada en plena acción, la cual termina por afectar al poeta, quien transeúnte o pasajero de un camión - debe obedecer el implacable mandato de las señales de tránsito. Después de la estrofa inicial, otras tres se van yuxtaponiendo mediante la conjunción " $y$ " con que inician algunos versos, con lo cual se construye una sintaxis que posee un sentido de acumulación y simultaneidad. Salta a la

12 Todas las citas de los poemas de El pentagrama eléctrico están tomadas de la versión del libro recopilada por Luis Mario Schneider en El estridentismo o una literatura de la estrategia (1997). 
vista, después de dos estrofas de alejandrinos y una de octosílabos, la aparición de un último octosílabo escrito en mayúsculas: “AALTO! EVITE PELIGRO”, que da paso a un par de decasílabos, cuya cadencia casi melancólica — debida a su extensión y al lugar que ocupan al final del poema - contrasta con el tono más bien impersonal de los versos anteriores. Después de esos imperativos, que funcionan como una suerte de pastiche mediante el cual un anuncio urbano irrumpe en el poema, ${ }^{13}$ la voz del poeta, hasta entonces en tercera persona, se transforma en un yo, el cual sufre una doble afectación derivada de la simultaneidad de sentidos que presenta la imagen; pues el "alma" que "se ha desparramado", "ante el mandato verde de tus ojos", puede ser entendida como un movimiento físico al cambiar la luz del semáforo, pero también como un movimiento afectivo producido por la contemplación de los ojos de una mujer.

A propósito de esta relación entre la ciudad y la voz poética, Luis Mario Schneider llama la atención sobre la presencia de un léxico poco acostumbrado entre los estridentistas, determinado acaso por la profesión del autor, quien recurre al uso de "sustantivos como seno, vientre, erección, epilepsia, flagelo, que suelen asociarse a adjetivos y verbos de parecidos significados. Todo ello crea un clima erótico y fisiológico que distingue sobremanera la poesía de Gallardo de la del resto de los estridentistas" (146). Sin embargo, la incorporación de estos términos no es lo único contrastante en la poesía del potosino. Una profunda tensión entre elementos aparentemente irreconciliables, entre lo nuevo y lo viejo, entre lo maquinal y lo viviente, entre lo funesto y lo promisorio recorre sus poemas. El canto a la "belleza actualista de las máquinas" nunca es unívoco, sino que entra en diálogo con motivos más tradicionales, estableciendo una serie de relaciones conflictivas entre un mundo y otro. Esta tensión es evidente en las imágenes en las que se funden

${ }^{13}$ En El joven de 1928, crónica vanguardista de la Ciudad de México, Salvador Novo comenta: "Hace poco hubo una fórmula de anuncio en los camiones. Junto a 'Pida usted su parada con anticipación', 'Evite peligro' decía; era una asociación contra los choques y los accidentes" (244). 
elementos naturales o humanos con otros de carácter tecnológico o propios de la vida urbana moderna, generalmente mediante la acción de verbos con significaciones violentas o destructivas. En El pentagrama eléctrico, la aparición de las estrellas es un "ametrallaje del crepúsculo", la luna es "metálica" o "esquirola / se ríe de los focos comunistas", "los árboles amarillos / boicotean las avenidas", "el viento peina sus crines en la lluvia / sobre la pirotecnia de todos los tejados", "miles de cocuyos" "rayan los bazares de la noche"; "una corriente voltaica / se desprende de la pila de las vértebras" de quienes bailan al ritmo del jazz, "los semáforos cirujanos / sangran las calles apopléticas", las ventanas se angustian frente a las luces de los autos y "suspendida de un trole" se arrastra la tristeza; "iLa vida — escribe el poeta en una imagen ejemplar- es un bostezo fugaz de gasolina!"' (441).

En palabras de List Arzubide, la metáfora estridentista procuraba dar forma a estas relaciones entre subjetividad y materia, entre materia y subjetividad:

Para nosotros [la imagen equivalente] fue, además, la síntesis de nuestra relación con lo que nos rodea y pudimos ir así de nosotros hacia las cosas y sucesos; introducir la vida ambiente en nuestro ser: animas los objetos para hacerlos decir lo subjetivo o dar a lo subjetivo una calidad material. (Elmovimiento 115)

Gallardo comparte esta idea. A propósito de la distancia entre el futurismo y el estridentismo, el poeta afirma: "También nuestro maquinismo es diferente. Marinetti lo considera en su forma externa y nosotros lo sentimos desde el interior, como algo emocional y cambiante" (cit. en López 52).

Los objetos de El pentagrama eléctrico no poseen un carácter meramente escenográfico, sino que suelen crear un vínculo con los habitantes de la ciudad o con la voz del poeta. "Escalamiento" es una excepción notable, pues en él no existe una presencia humana significativa, salvo por la mención de una "cosecha de noctámbulos". Toda la vitalidad está reservada a las cosas, las cuales son las protagonistas de esta estampa de una calle mojada, iluminada por 
los cruces y los reflejos de las luces de los autos, los semáforos y los letreros eléctricos:

\author{
ESCALAMIENTO \\ Ante la angustia de las ventanas \\ los autos chocan sus espadas \\ Y los semáforos cirujanos \\ sangran las calles apopléticas \\ inmunes al desagüe de los bars \\ Los teatros abren sus esclusas \\ sobre el arroyo congelado \\ $\mathrm{Y}$ en las redes de los timbres \\ hay cosechas de noctámbulos \\ Los gusanos fosfóricos \\ De los letreros eléctricos \\ escalaron el cielo. (444-5)
}

Sin embargo, esta no es la constante en la poesía de Gallardo. En "Carrousell", por ejemplo, aunque la voz poética no cobra la forma de un yo, se adivina una presencia humana en torno a la máquina, una presencia que completa y otorga sentido al cuadro presentado. En medio de una mañana dominical y festiva, la rotación cinemática del aparato crea la ilusión de unir lo disperso y, en su movimiento giratorio, congrega las miradas recíprocas de los niños y adultos que podemos imaginar alrededor de él; más aún, consigue borrar las preocupaciones de la semana laboral, y desdibujar sinestésicamente el tránsito del tiempo:

Carroussell

Girando en el pivote de un aire popular

El diorama cromático se integra en la unidad

y es un telar concéntrico de anhelos y miradas

Sobre la angustia del pasado

El tiempo derrite las horas

Que lacran la epístola dominical.

Un globo de hidrógeno

Ha plagiado los sueños pueriles 
Y el volantín automático

Es un jardín zoológico

Que trilla aires desusados

En la polifonía colorista

Hay una interferencia de sonidos. (442)

En "Cámara obscura", compuesto casi en su totalidad por versos cortos de arte menor que dan a las imágenes un carácter de instantaneidad, son más diáfanos los puentes que se tienden entre las cosas y el poeta. En una primera estrofa, de versos irregulares, se actualiza la atmósfera romántica de un amanecer que descubre a una voz poética ensoñada:

Sobre mi sueño horizontal

Cae la lluvia de una Torre

Un gallo barométrico

Desgrana la espiga del mañana. (441)

Una segunda estrofa, introducida por un verso que presenta la imagen doble de unas "Locomotoras - fantasmas", prepara el ambiente en el que se nos revelarán los movimientos interiores del poeta. Se puede entender que la marcha de las locomotoras, en su carácter fantasmal, forma parte de un paisaje sonoro moderno que irrumpe desde la lejanía, en el espacio silencioso en el que se halla la voz poética, la cual, descubrimos en los últimos dos versos, se encuentra contemplando melancólicamente la fotografía - "luna al magnesio"- ${ }^{14}$, de quien podríamos imaginar como su amada, figura que aparece en un contexto connotado por la lejanía y la distancia:

${ }^{14}$ Entendemos esta imagen como una sinécdoque de fotografía pensando en el título del poema y en el hecho de que todavía durante las primeras décadas del siglo XX, antes de la invención de la lámpara de flash, se utilizaban polvos de magnesio para producir luz artificial. En una entrada del diario de Federico Gamboa, del 15 de marzo de 1922, se lee, por ejemplo: "Preséntame Sassone a María Palou, y a algunos de su trompee. Besamanos, elogios mutuos, y fotografías al magnesio para la prensa" (59). 
Locomotoras - fantasmas

Acepillan las distancias

Y las leznas de los pitos

Taladran el silencio

Una lágrima de oro

Burila mi vidriera

Y la luna al magnesio

Me revela tu imagen. (441-2)

A diferencia de los poemas anteriores, aquí no son las cosas las que se humanizan sino un afecto el que se cosifica: la "lágrima de oro", la tristeza metalizada, surge en la contemplación de una imagen igualmente mecanizada, producto de una cámara obscura, que entrega al poeta la visión melancólica de la mujer amada, como si en su contacto con las cosas la interioridad se desdibujara para adquirir rasgos de lo material.

\section{La ciudad poliédrica y multánime}

La ciudad de Gallardo es también una ciudad múltiple y llena de contrastes, a veces una urbe, a veces un puerto, y sus espacios van de los primordialmente modernos, nocturnos y multitudinarios, como el cabaret, el cine y el teatro, a otros diurnos y familiares, como el jardín o el zoológico. Como afirma Silvia Pappe, “. . . los estridentistas no describen una ciudad para que la gente la conozca, sino que escriben en torno a las posibilidades, el potencial de lo urbano para que la gente que viva en alguna ciudad, se vea a sí misma en esta ciudad" (123). De este modo, la estridentópolis gallardeana se presenta como una geografía ambivalente donde el anhelo, el furor y el entusiasmo por lo moderno convive con una sensación de angustia, pérdida y desamparo.

En "Cabaret" encontramos una celebración de la vida moderna desarrollada en uno de los nuevos espacios nocturnos — como los "bars" y los "teatros" de "Escalamiento"-, inventados por la luz eléctrica: 
CABARET

El jazz extiende su lecho clandestino

y teje una maraña de deseos

Una corriente voltaica

se desprende de la pila de las vértebras

y vibra en los timbres de los senos

Las pupilas orgiastas

eyaculan miradas

Olvidada pareja

bebe su romanticismo

en vasos de cerveza

Los reflectores contusos

rompen la piñata de la aurora

que vierte sobre la orgía

sus confetis polícromos

Afuera una bandada de autos

BOZ-TE-ZA

Y el Cabaret del

cielo

chimea las estrellas. (442-3)

Para Rashkin, "más que describir el deseo o la experiencia erótica, estos versos combinan metáforas fisiológicas y sexuales con la imaginería tecnológica del estridentismo. Si La Señorita Etcétera de Arqueles Vela se lamentaba por la mecanización de la intimidad y del cuerpo humano, la poesía de Gallardo satura con mortalidad carnal el ambiente moderno y sus artefactos" (251). El poema muestra el entrelazamiento del adentro y el afuera, de lo corporal y lo tecnológico, de lo natural y lo artificial. La noche al interior del cabaret transcurre con una multitud de cuerpos electrificados, erotizados, por la música de jazz, el alcohol y las luces; cuerpos que además no parecen gobernarse a sí mismos ni a las cosas, sino que son dominados por estas. Afuera predomina el ruido de los autos, taxis quizás que esperan a los noctámbulos, y el cielo, que tampoco escapa a los influjos de lo moderno, se convierte en una extensión del cabaret. 
En otros momentos de la poesía de Gallardo, sin embargo, la ciudad y sus nuevos actores aparecen con un rostro amenazador y deshumanizante. En "Corto-circuito" se insinúa la fragilidad de la ciudad moderna, una "ciudad de azúcar" que una noche de lluvia se ha quedado sin luz eléctrica:

El viento peina sus crines en la lluvia sobre la pirotecnia de todos los tejados y en tanto que los trenes sufren de catalepsia la ciudad de azúcar se reviene en la sombra

Los fanales cortan las trincheras alambradas y estrellan las lunas del asfalto. (446)

La descripción de los versos iniciales se interrumpe y al final de la primera estrofa aparecen un yo y un tú — quizás unos amantes separados-, como si el retraimiento de lo moderno permitiera la emergencia de lo interior — el amor, la nostalgia_, en este caso a través de la memoria:

\section{La ausencia reiterada}

me arrojó tu recuerdo (446)

No obstante, apenas se restablece la corriente eléctrica — calificada paradójicamente como gloriosa-, el mundo moderno resurge con toda su violencia, consiguiendo borrar el recuerdo de la amada y llevando al poeta de vuelta a un mundo enajenado donde es imposible el encuentro con el otro y acaso con uno mismo:

De pronto ha florecido la gloria edisoniana

y en un arco voltaico se ahorca mi nostalgia

La vida quema sobre los baches sus misivas románticas. (446)

“Alarma!!", por otra parte, es un poema de tonos bélicos que muestra a una ciudad convulsionada por los movimientos sociales 
en tiempos de la rebelión delahuertista o evocadora de los no tan lejanos días de la Revolución, de los cuales Gallardo fue testigo en primera fila. Se trata de una ciudad similar a la que Maples Arce recrea en Urbe. Súper-poema bolchevique en cinco cantos (1924), el poema que escribió después de observar a una manifestación obrera marchando por las calles de la Ciudad de México. Aquella jornada, recuperada por el veracruzano en sus memorias, bien podría ofrecernos una pintura del ambiente en que se desenvuelve el poema de Gallardo:

Un primero de mayo, por la tarde, regresaba de Mixcoac a pie, pues no había servicio de transportes, totalmente paralizados por la manifestación obrera. El viento arremolinaba el polvo de las barriadas y grupos proletarios regresaban cargando sus pancartas y calicós con lemas reivindicados y banderas rojas y negras. Oleadas de obreros vestidos de mezclilla se sucedían constantemente y se escuchaban vítores a sus líderes y confederaciones. . . . Las disensiones sindicales, las agitaciones políticas y las amenazas de la guerra civil se cernían sobre nuestros destinos. En la Cámara de Diputados, la razón de los discursos se trocaba sorpresivamente en un relámpago de pistolas. Los entorpecedores del progreso de México fanatizaban a grupos de militares y políticos para adueñarse del poder, los obreros desfilaban en manifestaciones de alerta, y, por mi parte, miraba estos espectáculos y reflexionaba sobre las circunstancias y responsabilidades de los hombres que podrían influir en los destinos nacionales. Cuando llegué a mi casa, bajo las fuerzas estimulantes, me puse a escribir un canto en que latía la esperanza y la desesperación. (Soberana 100-1)

De acuerdo con Evodio Escalante, los estridentistas se abrieron a "la nueva realidad que surge con los procesos revolucionarios que están transformando de manera compleja al país, aunque por otro lado hay algo en este ascenso oscuro ... de las masas que los estremece y provoca en ellos un desasosiego estrictamente contem- 
poráneo" (47). Esa angustia, señalada por el crítico mexicano, está presente en "Alarma!!", donde se funden en la violencia el paisaje natural (los árboles, las estrellas, la luna) y el metonímico de las multitudes obreras (las "banderas negras de las fábricas", la "ira roja de las calderas"):

Los árboles amarillos

boicotean las avenidas

Las banderas negras de las fábricas

sobre la ira roja de las calderas

Cañones antiaéreos

con granadas de estrellas

$Y$ esa luna derretida

que acidula de azul los horizontes. (444)

La ciudad, que en otros poemas aparece revolucionada por la intervención de lo tecnológico, aquí lo hace por la acción de uno de los nuevos personajes que ella misma ha engendrado: las masas obreras. A diferencia de Urbe, "Alarma!!" no es ambivalente a la hora de describir la tribulación que la ciudad experimenta ante la agitación social:

Por las calles paroxistas

la alarma riega su horror

¡Dios mío! la angustia estrangula

todas las gargantas

Y en esa laminé satánica

la epilepsia de los edificios (444)

La modernidad parece tocar sus límites al enfrentarse con esos sujetos modernos que la cuestionan como promesa de un futuro mejor. Los edificios, otras veces portentosos, se muestran epilépticos, convulsionados, en medio de una escena que el poeta llega a calificar como "satánica". Como en otros poemas de Gallardo, la descripción impersonal cede paso, hacia el final, a la aparición de la voz poética, que nuevamente incorpora a una primera y una segunda persona del singular: 
La injuria arrastra por mis venas

todo un rosario de brasas

Y el corro brusco de tus palabras

es un flagelo sádico. (444)

En estos últimos versos la agitación se desplaza de lo visual a lo auditivo, más específicamente a lo lingüístico. La "laminé satánica" abre paso a la "injuria" y al "flagelo sádico" del "corro brusco de tus palabras". Las injurias, las mentiras, que inflaman la sangre del poeta, ¿son acaso las de los rebeldes delahuertistas levantados contra el gobierno de Álvaro Obregón o son las de los obreros que descreen de la promisión de lo moderno? El "corro brusco de palabras", ¿pertenece a esa figura femenina que aparece insinuada en otros momentos del poemario o son las palabras de una ciudad insurrecta que exhibe su violencia sin ambages? Siguiendo la crítica de Escalante a Urbe, podríamos pensar que, si se trata de una mujer, estamos ante una suerte de "sacrificio libidinal"; es decir, ante la concepción de que "la modernidad solo puede conseguirse a cambio de desprenderse de la figura de la mujer amada, a quien de algún modo se concibe como un lastre del que hay que prescindir" (51). En lo que toca a Gallardo la idea del sacrificio no resulta tan clara, pues ese tú, que puede leerse como un tú femenino, ocupa un lugar ambiguo, a veces afirmativo como en "Jardín" "'Y en el paisaje de tus pupilas / Todas las primaveras regresaron") o en "Film" ("Astrólogos benignos, tus ojos de turquesa / Marcaron en mi sino igneal seña propicia!’), y a veces derogativo o melancólico, como en "Alarma!!", "Naufragio" "“Y pensar que a tus ojos / se los ha tragado el mar") y "Corto-circuito" ("La vida quema sobre los baches / sus misivas románticas”), pero siempre contrastante —apareciendo invariablemente en los versos de cierre- con las imágenes tecnologizadas de los poemas. En cualquiera de los casos, en "Alarma!!" las tensiones de la vida moderna, expresadas en otros poemas del libro, se resuelven en su forma más terrible y muestran las contradicciones del nuevo siglo.

La ciudad estridentista de Salvador Gallardo, con sus oscilaciones entre lo interior y lo exterior, entre lo maquinal y lo humano, 
surge como un territorio poliédrico y ambiguo, lleno de matices y contrastes, donde se expresa el entusiasmo, pero también los temores de un grupo de jóvenes que a comienzos del siglo XX mexicano se arrojaron al incierto abismo de lo moderno.

\section{Bibliografía}

Alva de la Canal, Ramón, ilustrador. Portada de El pentagrama eléctrico. Poemas de Salvador Gallardo. German List Arzubide, 1925. Créditos: Museo Nacional de Arte, INBA, donación de Blanca Vermeersch Vda. de Maples Arce, 66.111.6.112/objects/2853/ el-pentagrama-electrico-poemas-de-salvador-gallardo-ed-ge?c$\mathrm{tx}=9138 \mathrm{c} 8 \mathrm{~b} 5-\mathrm{a} 029-43 \mathrm{~b} 0-9 \mathrm{bf} 6-1 \mathrm{dab} 25141 \mathrm{c} 25 \& \mathrm{idx}=0$

Baudelaire, Charles. Elpintor de la vida moderna. Editado por Antonio Pizza y Daniel Aragó, prólogo de Antonio Pizza, traducción de Alcira Saavedra, Colegio Oficial de Aparejadores y Arquitectos Técnicos / Librería Yerba / Cajamurcia, 1995.

Bürger, Peter. Teoría de la vanguardia. Traducción de Jorge García, prólogo de Helio Piñón, Península, 1987.

Corte Velasco, Clemencia. La poética del estridentismo ante la crítica. Benemérita Universidad Autónoma de Puebla, 2003.

Escalante, Evodio. Elevación y caída del estridentismo. Ediciones sin Nombre / Conaculta, 2002.

Gallardo, Salvador. El pentagrama eléctrico. Schneider, 1997, pp. 440447.

Gallardo, Salvador et al. Manifiesto Estridentista No. 3. Schneider, pp. 278-9.

Gamboa, Federico. "15 de marzo". Mi diario VII (1920-1930). Mucho de mi vida y algo de la otros, Conaculta, 1996, p. 59.

Garone-Gravier, Marina. "La tipografía estridentista: diseño que huele a modernidad y dinamismo". Nueva vistas y visitas al estridentismo, coordinado por Daniar Chávez y Vicente Quirarte, Universidad Autónoma del Estado de México, 2014, pp. 111-139.

Hadatty Mora, Yanna. La ciudad paroxista. Prosa mexicana de vanguardia (1921-1932). Universidad Nacional Autónoma de México, 2009. 
List Arzubide, Germán. El movimiento estridentista. Secretaría de Educación Pública, 1987. . Esquina. Schneider, pp. 400-412. . "Peldaño". Gallardo, El pentagrama eléctrico, pp. 9-11.

López, Leticia. Un suspiro fugaz de gasolina. Los murmullos estridentes de Salvador Gallardo. Instituto Cultural de Aguascalientes, 1998.

Maples Arce, Manuel. Actual No. 1, Hoja de vanguardia, Comprimido estridentista de Manuel Maples Arce. Schneider, pp. 67-75.

. Soberana juventud: (Memorias II). Universidad Veracruzana, 2010.

Novo, Salvador. El joven. Viajes y ensayos. Tomo I, compilado por Sergio González Rodríguez, notas introductorias por Sergio González Rodríguez, Antonio Saborti y Mary K. Long, Fondo de Cultura Económica, 1996, pp. 238-254.

Pappe, Silvia. Estridentópolis: urbanización y montaje. Universidad Autónoma Metropolitana / Azcapotzalco, 2006.

Poggioli, Renato. Teoría del arte de vanguardia. Traducción de Rosa Chacel, Revista de Occidente, 1964.

Quirarte, Vicente. Elogio de la calle. Biografía literaria de la Ciudad de México, 1850-1992. Cal y Arena, 2001.

Rashkin, Elissa J. La aventura estridentista. Historia cultural de una vanguardia. Traducción de Daniel Alberto Castillo Reynoso y Víctor Altamirano, Fondo de Cultura Económica / Universidad Veracruzana / Universidad Autónoma Metropolitana, 2014.

Sánchez Pineda, Ernesto. "Prolegómenos al Ateneo de la Juventud y la figura del intelectual moderno (1900-1909)". 2018. El Colegio de San Luis, Tesis de doctorado, dirigida por Antonio Cajero Vázquez, colsan.repositorioinstitucional.mx/jspui/ bitstream/1013/698/1/Proleg\%C3\%B3menos\%20al\%20Ateneo $\% 20$ de $\% 201 \mathrm{a} \% 20 J u v e n t u d . p d f$

Schneider, Luis Mario. El estridentismo o una literatura de la estrategia. Conaculta, 1997.

Stanton, Anthony. "Los Contemporáneos y el debate en torno a la poesía pura". Los Contemporáneos en el laberinto de la crítica, editado por Rafael Olea Franco y Anthony Stanton, El Colegio de México, 1994, pp. 27-52. 